\title{
Role of sunflower production and processing in import substitution
}

\author{
Alexey Ilyin, and Karina Shtokolova \\ Kursk State Agricultural Academy named after I.I. Ivanov, d. 70, st. Karl Marx, Kursk, 305021, Russia
}

\begin{abstract}
The role of sunflower production and processing within the framework of import substitution is extremely important for food industry: in addition to the production of sunflower oil and its fractions, sunflower and its by-products are actively used in confectionery industry, and waste is a valuable feed for farm animals. The study considers the trends in sunflower cultivation and processing in Russia, as well as the development of export and import since the beginning of the food embargo. Today, sunflower is one of the most dynamically developing agricultural crops in Russia, as evidenced by the positive dynamics of sown areas and gross yield. At the same time, in recent years, sunflower cultivation has intensified, as a result of which its yield has increased by $40 \%$ over the past 6 years. Among other types of crops actively grown in Russia, sunflower today demonstrates quite high rates, second only to soy. With the dynamic development of sunflower production and processing in the country, there has been a change in the vector of agricultural production of this crop as part of the import substitution strategy and food security. Whereas previously the main strategic objective was to increase the level of self-sufficiency and ensure the country's domestic needs for sunflower and its by-products, today, as production develops, there is a transition to an export-oriented model.
\end{abstract}

\section{Introduction}

Food security in the current political situation has become one of the key priorities of Russia's strategic development. The relevance of this direction is caused by the deterioration of the geopolitical situation against the background of the conflict with Ukraine due to the annexation of Crimea to Russia, as a result of which a number of anti-Russian sanctions were applied to our country, which negatively affected the economy and endangered food security.

Since the agricultural sector for Russia is traditionally fundamental in food supply, the increase in domestic agricultural and industrial potential under export-import restrictions has come to the fore. While there had previously been close integration with other countries in the agricultural sector, and imports in a number of areas had been substantial, the sanctions caused the need to increase the level of self-sufficiency for all major types of food products.

As a result, food import substitution has become the most important task, the implementation of which largely depends on the autonomy and socio-economic development of the country. One of the meaningful strides towards import substitution was the introduction of a food embargo in response to anti-Russian sanctions. In addition to a direct negative impact on foreign trade of former partner countries this decision also had a positive impact on the Russian economy thus protecting domestic producers from import competition and forming all the necessary conditions for active production increase.
In recent years, in addition to increased volume of Russian traditional crops, such as grain and sugar beets, other, previously less popular crops began to be actively developed as part of the import substitution strategy. One of such directions is oilseeds, in particular sunflower, the cultivation volume of which in recent years has grown significantly [1].

The role of sunflower production and processing within the framework of import substitution lies is extremely high important for food industry. In addition to the direct sale of sunflower seeds, as well as the production of sunflower oil and its fractions, sunflower and its by-products are actively used in confectionery industry, and waste (anthodium, sunflower oil feed, sunflower meal, husk sunflower seeds) form the basis for secondary production. Sunflower processing waste is valuable for farm animals, since it is rich in vitamins and microelements, and also allows farmers reducing their costs without losing animal productivity. As a result, sunflower production and processing is almost waste-free, which makes this culture attractive within the agroindustrial complex. In this regard, the intensification of sunflower production and processing in Russia is particularly important not only in ensuring food import substitution, but is also in developing and maintaining the agricultural economy.

\section{Materials and Methods}

The data of the Yearbook of Statistics on the cultivation and processing of sunflower in Russia, as well as on the

\footnotetext{
Corresponding author: karina.shtokolova@mail.ru
} 
dynamics of export-import operations in 2014-2019 were used in the study [2]. The study period was determined by the introduction of a food embargo in Russia in 2014 in response to anti-Russian sanctions, which brought up the development of import substitution in the field of food supply to date. The assessment of the development of sunflower production and its processing products was carried out using a large list of methods and approaches, including the dynamics analysis, comparative and logical analyses.

\section{Results and Discussion}

The total sown area of sunflower in Russia over the past 6 years has a steady upward trend. If in 2014 the volume of sunflower crops amounted to 6911 thousand hectares, then by 2019 it increased to 8584 thousand hectares, which illustrates a total increase of $24.2 \%$ or 1673 thousand hectares. At the same time, the share of sown areas of sunflower in Russia in the total volume of sown areas has a stable upward trend. If in 2014-2015 the share of sunflower was $8.8 \%$, then already in 2017 it exceeded $10 \%$, and by 2019 reached $10.7 \%$. In general, the increase in the share of sunflower crops in the total sown area in the country amounted to almost $2 \%$ over 6 years (Fig. 1).

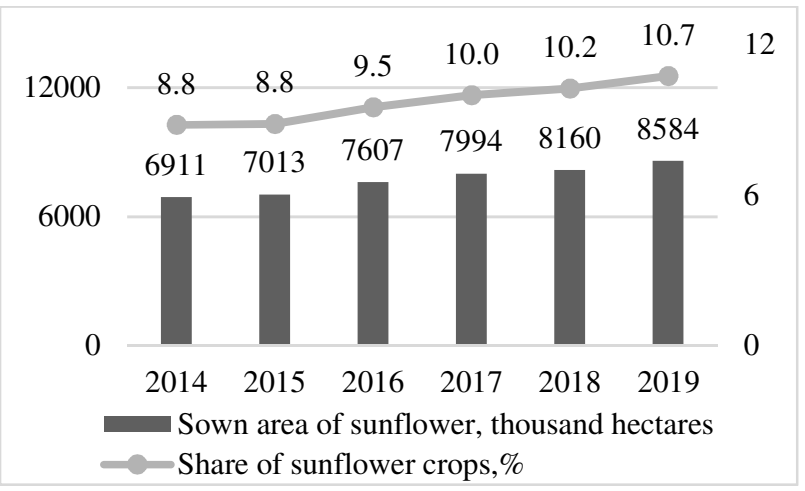

Fig. 1. Dynamics of the size and share of sown areas of sunflower in the Russian Federation in 2014-2019

Besides, the yield of sunflower in the country also has a positive upward trend, which illustrates an increase in the efficiency of growing this crop. Thus, in 2014, sunflower harvest from one hectare was $13.1 \mathrm{hkg} / \mathrm{ha}$, and by 2016 it had grown to $15.1 \mathrm{hkg} / \mathrm{ha}$. In 2017 , the yields decreased to $14.5 \mathrm{hkg} / \mathrm{ha}$. In the last 2 years, there has again been a trend towards an increase in sunflower yields to $16 \mathrm{hkg} / \mathrm{ha}$ and to $18.3 \mathrm{hkg} / \mathrm{ha}$ in $2018-2019$, respectively. As a result, sunflower yield in 2019 is the highest over the last 6 years, and the overall increase in this indicator during the study period was almost $40 \%$.

The gross sunflower harvest in Russia during the study period, although it varied wave-like, has a general upward trend. In 2014, the total harvest of sunflower seeds amounted to 8.5 thousand tons, and by 2016 this indicator increased to 11 thousand tons. Despite an insignificant decrease in this indicator in 2017, in the last 2 years there has been an increase in gross sunflower harvest up to 12.8 thousand tons and 15.4 thousand tons in 2018-2019, respectively. The wave-like nature of the dynamics of gross sunflower harvest in the Russian Federation is caused by a similar change in the yield level of this crop (Fig. 2).

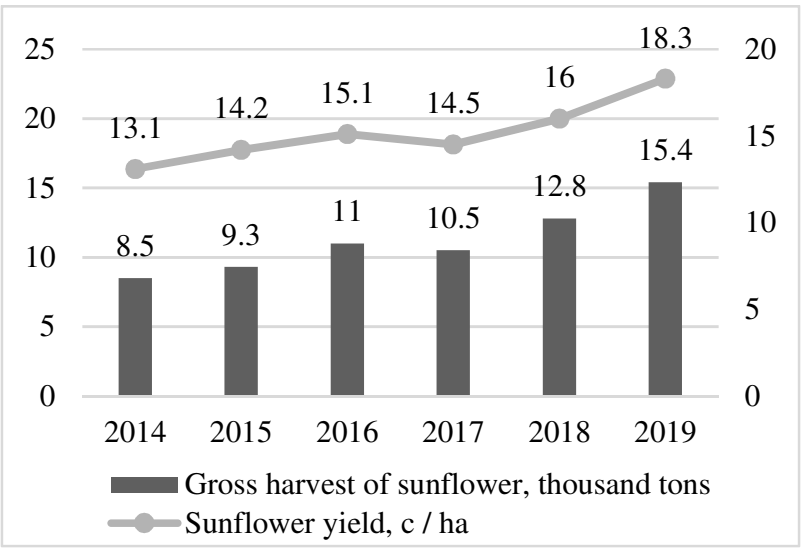

Fig. 2. Dynamics of gross sunflower harvest and yield in the Russian Federation in 2014-2019

Therefore, it can be said that today sunflower production is one of the most dynamically developing agricultural areas. Comparing the growth rate of sown areas of the main crops grown in Russia over the past 6 years, it may be noted that in terms of growth, sunflower is second only to soybean, the sown area of which has doubled, while sunflower - only by a quarter. At the same time, the increase in sown areas of grain crops is insignificant $(1.1 \%)$, and sugar beets are almost equal to the level of sunflower crops (Fig. 3).

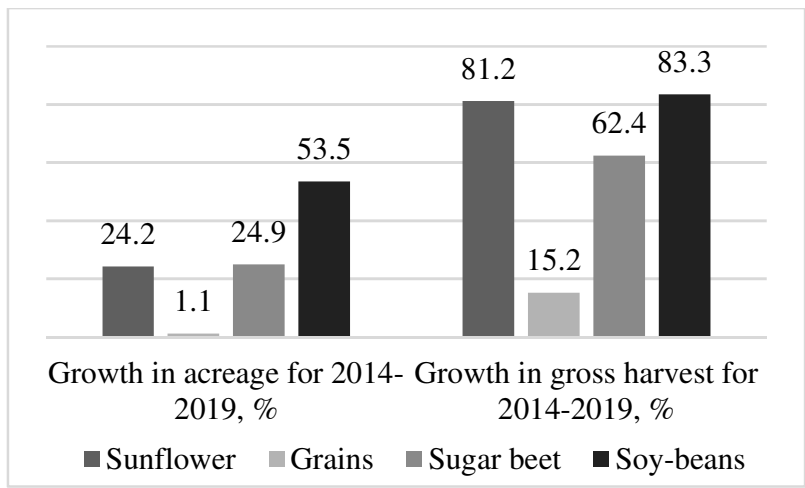

Fig. 3. Estimated growth of sown areas and gross sunflower harvest compared to the main crops in the Russian Federation over 2014-2019

Soy-beans and sunflower are also characterized by the increase in gross harvest over 6 years, where this indicator exceeded $80 \%$, while the increase in gross sugar beet harvest was $62.4 \%$, and cereals - $15.2 \%$. This is determined by the fact that these crops have relatively recently received an impetus for development, while grain and sugar beet have already exhausted extensive and basic intensive factors to increase their gross harvest. It should be noted that the limited domestic capacity of the market negatively affects grain and sugar beet gross harvest. For beet sugar, this is generally a determining factor in limiting the demand for sugar beets, since Russian sugar is not competitive in most countries compared to cane [3]. 
This problem is also typical for many types of grain crops, among which only wheat has a high export potential, which determines the effectiveness of its cultivation and the desire of farmers to use it as a priority crop in crop rotation [4].

High increase in the main indicators of sunflower cultivation also indicates that sunflower is now becoming an increasingly significant crop more actively involved in crop rotation. Accordingly, an increase in the volume of gross sunflower harvest in Russia is also noted in the production of vegetable oils and their unrefined fractions. Thus, in 2014, the production of vegetable oil amounted to 4660 thousand tons, and in 2016 it exceeded 5200 thousand tons. In the last 3 years, the upward trend has continued, as a result of which by 2019 the volume of vegetable oil production reached 6766 thousand tons, which is the highest during the study period. Besides, the total increase in the production volume of vegetable oils and their unrefined fractions in Russia over 6 years exceeded $45.2 \%$ (Fig. 4).

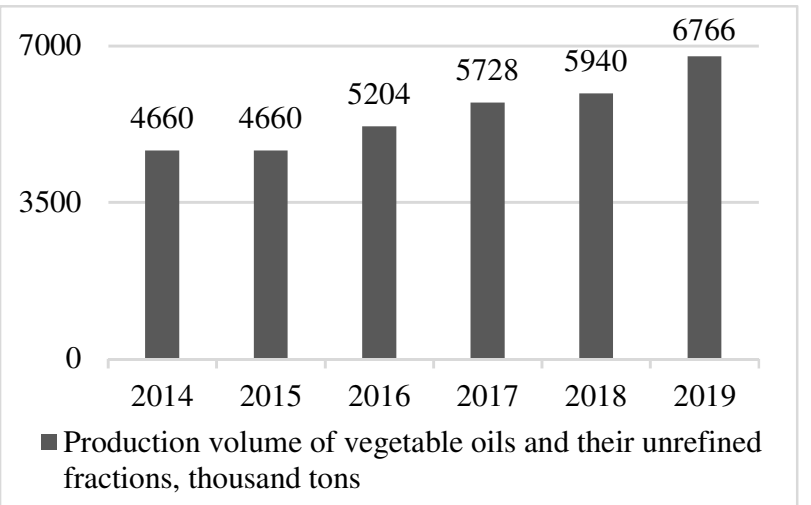

Fig. 4. Dynamics of production of vegetable oils and their unrefined fractions in the Russian Federation in 2014-2019

With respect to the development of foreign trade, it is worth noting that the export volume of sunflower oil and its unrefined fractions, both by value and volume, has an overall upward trend. At the beginning of the study period, sunflower oil exports amounted to 1.67 million tons, which is $\$ 1.46$ billion. In 2015 , the volume of exports fell to 1.45 million tons, and in value terms - to 1.19 billion dollars, due to the deterioration of the foreign policy situation and the inevitable decline in foreign trade. In 2016-2017 there was an increase in the volume of sunflower oil exports up to 2.33 million tons, which is equal to $\$ 1.78$ billion. In 2018 , there was another decline in foreign trade activity, as a result of which the volume of exports fell to 2.11 million tons, and by value - to $\$ 1.61$ billion (Fig. 5).

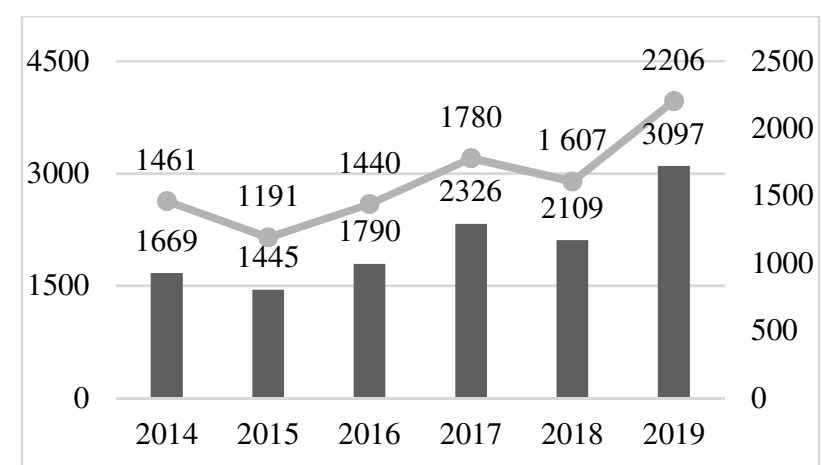

Export of sunflower oil and its fractions, thousand tons - Export of sunflower oil and its fractions, mln USD

Fig. 5. Dynamics of Russian exports of sunflower oil and its unrefined fractions in 2014-2019

In 2019, the growth of sunflower oil exports was again positive, bringing the figure to 3.1 million tons, which is $\$ 2.21$ billion. As a result, during the study period there was an increase in the physical volume of sunflower oil exports by $85.6 \%$, and in value - by $51 \%$, which illustrates the active development of its export.

The share of sunflower oil exports in the total export of food products, although it varies wave-like in the study period, has an overall upward trend. In 2014, sunflower oil accounted for about $7.7 \%$ of food exports, and in 2015 this figure fell to $7.3 \%$ due to a decline in foreign trade associated with sanctions. However, already in 20162017, the share of exports of sunflower processing products increased to $8.4-8.6 \%$, respectively. In 2018, there was another decline in export activity, as a result of which the share of sunflower oil in the total export structure decreased to $6.4 \%$ (Fig. 6).

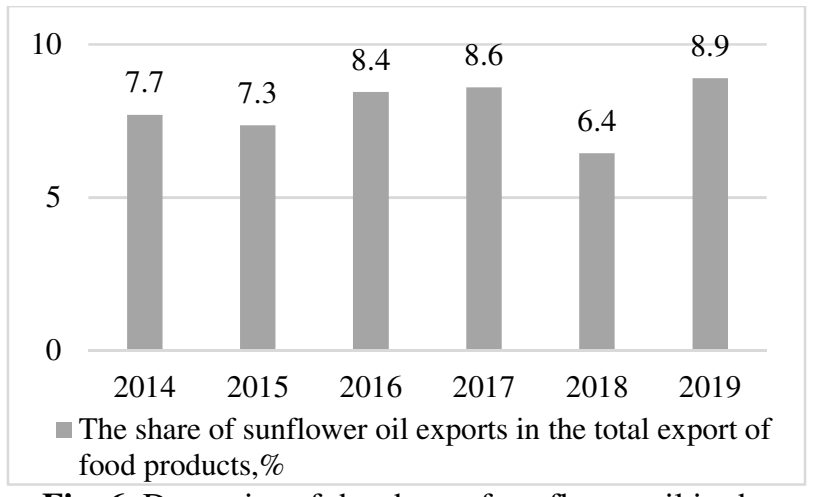

Fig. 6. Dynamics of the share of sunflower oil in the total structure of food exports in the Russian Federation in 2014-2019

In 2019, there was another increase in the share of sunflower in the structure of food exports to $8.9 \%$, which is the largest value for the period under study.

Today, the development of sunflower export is an important stage, following the import substitution within the country. An active increase in the production and processing of sunflower will not only ensure the country's domestic needs to the full, but will also contribute to the development of foreign trade. Hence, the transition from import dependence to export-oriented trade becomes promising from the point of view of ensuring economic 
security and developing entrepreneurship. However, in order to develop sunflower exports, it is necessary to solve a set of problems characteristic of the main export product of agriculture - grain. The main ones include the inconsistency of the transport and logistics infrastructure with the strategic objectives of increasing the export of Russian food thus predetermining the decrease in its competitiveness and efficiency [5].

In the conditions of the food embargo and the import substitution strategy, it should be logical for Russia to reduce the import of sunflower oil and its processed products. At the same time, the assessment of the volume of imports of sunflower processing products showed the wave-like nature related to the change in the indicator. In 2014, the volume of imports of sunflower oil in the Russian Federation amounted to 8.8 thousand tons, which is equal to $\$ 11$ million. In 2015-2016 there was a decrease in the physical volume of sunflower oil imports to 3.4-5.9 thousand tons or 3.8-5 million dollars, which is largely caused by the beginning of import substitution in the country.

However, 2017-2018 saw a significant increase in Russia's import of sunflower oil and its unrefined fractions, as a result of which its volume reached 25.7 thousand tons, which is the largest in the study period. At the same time, the value of imports in 2017-2018 amounted to \$17.1-16.7 million. In 2019, there was another decrease in the volume of imports of sunflower oil, as a result of which its physical volume amounted to 2.5 thousand tons, and the value -1.9 million dollars (Fig. $7)$.

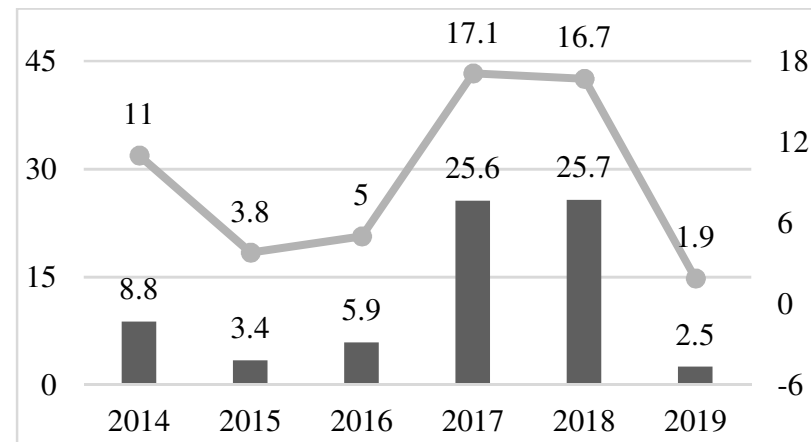

Import of sunflower oil and its fractions, thousand tons - Import of sunflower oil and its fractions, mln USD

Fig. 7. Dynamics of import of sunflower oil and its unrefined fractions into the Russian Federation in 20142019

Consequently, despite the active development of sunflower production and processing in Russia in recent years, as evidenced by the increase in crop, yield and gross harvest, the problem of import substitution of this type of food product is still not fully solved, since sunflower oils and their fractions are continuously imported, although its volumes vary significantly, being low in comparison with exports. This demonstrates that the current level of sunflower production and processing does not fully meet the domestic needs of the country and requires the search for reserves to strengthen the domestic capacity.

\section{Conclusion}

Today, sunflower is one of the most dynamically developing agricultural crops in Russia, as evidenced by the positive dynamics of sown areas and gross harvest. Besides, in recent years, sunflower cultivation has intensified, as a result of which its yield has increased by $40 \%$ over the past 6 years. Among other types of crops actively grown in Russia, sunflower today shows high rates, second only to soy. This indicates that the role of sunflower in the country's food supply is growing. In turn, positive trends in the cultivation of sunflower seeds contributed to the growth in its processing. At the same time, the production of sunflower oil and its unrefined fractions in Russia also increased, reaching 6.8 million tons by 2019.

With the dynamic development of sunflower production and processing in the country, there has been a change in the vector of agricultural production of this crop as part of the import substitution strategy and food security. Whereas previously the main strategic objective was to increase the level of self-sufficiency and ensure the country's domestic needs for sunflower and its byproducts, today, as production develops, there is a transition to an export-oriented model. Moreover, the export of sunflower is particularly important not as raw materials, but in the form of its processed products, since this will contribute to the growth of gross added value and increase the economic efficiency of production. Despite the fact that sunflower is a fairly heavy crop for soil, its production for business is highly profitable due to its nonwastefulness, and is also of practical importance for livestock industries.

Therefore, at the current stage, the improvement of sunflower production and processing seems quite relevant, which will form new opportunities for the development of this area. Here the high importance is given to the mechanisms of state regulation, which today for the most part are nominal and low-efficient. Hence, improving the system of state regulation of sunflower production and processing based on export-oriented cultivation of crops comes to the fore.

\section{References}

1. K.V. Shtokolova, M.A. Fedulov, Bulletin of Kursk State Agricultural Academy, 3, 139-144 (2021).

2. Russian Yearbook of Statistics. 2020: Statistics Digest (Moscow, 2020).

3. D. Zyukin, O. Svyatova, R. Soloshenko, Economic Annals-XXI, 161 (9-10), 47-50 (2016).

4. D.A. Zyukin, O.N. Pronskaya, O.V. Svyatova, A.A. Golovin, O.V. Pshenichnikova, O.V. Petrushina, Revista de la universidad del Zulia, 12(32), 87-101 (2021).

5. D. Zyukin, O. Svyatova, E. Zolotareva, A. Bystritskaya, A. Alyokhina, Amazonia Investiga, 9(25), 461-470 (2020). 